\title{
Sala de aula e teceduras subjetivas*
}

\author{
Vera Lúcia Blum
}

Universidade Federal de Mato Grosso

\section{Resumo}

0 propósito deste artigo é pensar a tarefa docente tendo como foco as vicissitudes a que a relação docente-discente está submetida e as quais desviam alunos e professores dos ideais de ordem e de harmonia. Com o objetivo de analisar os fluxos intersubjetivos em sala de aula, abordam-se aspectos da psicodinâmica grupal com o uso das noções psicanalíticas de grupo de suposto básico e de identificação projetiva. Com esse procedimento, pretende-se ao mesmo tempo sondar até que ponto noções eficazes na clínica psicanalítica podem ser úteis para analisar e elaborar situações pertencentes ao campo da Educação, em particular, à sala de aula concebida aqui como espaço de produção de intercorrências psíquicas. Procura-se pensar o espaço intersubjetivo segundo uma lógica que considere a criação de uma terceiridade no ensinar e aprender. Introduz-se a noção de "terceira voz" (Ogden) para indicar a criação e recriação do outro intersubjetivo, que faz da atividade docente uma experiência geradora de turbulência emocional com efeitos diversos nas constituições subjetivas. 0 enrijecimento identitário, com o concomitante desdém e intolerância à diferença, pode ser uma forma de reagir àquilo que escapa ao controle e à previsibilidade e que enfraquece desse modo os movimentos transformacionais implicados no processo de aprendizagem.

\section{Palavras-chave}

Inconsciente - Grupo de suposto básico - Identificação projetiva Terceira voz.

\footnotetext{
Correspondência:

Vera Lúcia Blum

Universidade Fed. de Mato Grosso

Av. Fernando Correa da Costa, s/n

e-mail: verablum@cpd.ufmt.br
} 


\section{Classroom and subjective weavings*}

Vera Lúcia Blum

Universidade Federal de Mato Grosso

\begin{abstract}
The objective of this article is to think the task of teaching under the focus of the vicissitudes to which the teacher-student relationship is subjected, which steer pupils and teachers away from the ideals of order and harmony. With the purpose of analyzing the intersubjective flows in the classroom, aspects of group psychodynamics are investigated with the use of the psychoanalytic notions of basic assumption group and of projective identification. With this procedure, we want at the same time to probe to which extent notions that are efficacious in psychoanalytic clinic can be useful to analyze and to understand situations that belong to the field of education, and in particular the classroom, seen here as a space for the production of psychic inter-occurrences. We try to think the intersubjective space according to a logic that considers the creation of a third party in teaching and learning. We introduce the notion of a "third voice" (Ogden) to denote the creation and re-creation of the intersubjective other with various effects on the subjective constitutions. The identitary stiffening, along with the attending disdain and intolerance to difference, can be a form of reacting to that which escapes from control and predictability, thereby weakening the transformational movements implicated in the process of learning.
\end{abstract}

\section{Keywords}

Unconscious - Basic assumption group - Projective identification Third voice.

\section{Contact:}

Vera Lúcia Blum

Universidade Fed. de Mato Grosso

Av. Fernando Correa da Costa, s/n

e-mail: verablum@cpd.ufmt.br
* The author wishes to thank Professor Ivani Blum for reviewing the manuscript. 
Quem aconchegará o necessitado contador de histórias para que este possa receber o desamparo de quem precisa dessas histórias para crescer? (Nosek, 2004, p. 39)

Em artigo dedicado à psicologia do escolar, escrito para um volume coletivo em comemoração dos cinqüenta anos da escola onde estudou dos 9 aos 17 anos, Freud (1974a) revela:

É difícil dizer se o que exerceu maior influência sobre nós e teve importância maior foi a nossa preocupação pelas ciências que nos eram ensinadas, ou pela personalidade de nossos mestres. É verdade, no mínimo, que esta segunda preocupação constituía uma corrente oculta e constante em todos nós e, para muitos, os caminhos das ciências passavam apenas através de nossos professores. (p. 286)

No decorrer do texto, Freud (1914) deixa entrever que a personalidade à qual se refere não diz respeito à pessoa em si do professor, mas ao suporte que ele representa para a transferência de laços emocionais muito antigos e nele atualizados e sobre a qual ele não tem controle. Embora o docente não tenha controle sobre o papel que desempenha na vida psíquica de seus alunos, ele não pode deixar de responder aos efeitos nele provocados pelas fantasias destes. Da qualidade das respostas depende em parte o desejo dos alunos de aprender.

Meu objetivo neste artigo é pensar a tarefa docente pondo em cena algumas forças que, dos bastidores, extraviam, da intencionalidade consciente, os protagonistas da ação educativa. A fim de pensar os fluxos intersubjetivos em sala de aula, faço uso de concepções desenvolvidas por diferentes psicanalistas e baseadas em suas respectivas clínicas. Com esse procedimento, pretendo, ao mesmo tempo, sondar até que ponto noções eficazes na clínica psicanalítica podem ser úteis para analisar e elaborar situações pertencentes ao campo da Educação, em particular, à sala de aula concebida aqui como espaço de produção de contingências interpsíquicas.
Se é verdade que as doutrinas pedagógicas buscam a ordem, o controle e a previsibilidade do desenvolvimento cognitivo e emocional do educando, então o escopo da educação, materializada nos diferentes projetos pedagógicos, é a dimensão egóica, racional, do psiquismo humano. Assim, o extravio a que estamos submetidos diz respeito a forças psíquicas cuja ação não se pode controlar e delas só é possível ter notícia pelos efeitos que venham a produzir. A impossibilidade de controlar os efeitos das forças inconscientes é vivida, com maior ou menor intensidade, como traumática, justamente porque tais efeitos ameaçam de esfacelamento as couraças identitárias protetoras da auto-imagem, que é sempre egóica. 0 enrijecimento identitário, com o concomitante desdém e intolerância à diferença, pode ser, infelizmente, uma forma de reagir àquilo que escapa ao controle e à previsibilidade. Um modo menos dissociado de lidar com a imprevisibilidade das forças inconscientes próprias e alheias é suportar seus desarranjos, é ligá-las com a formação de rotas inusitadas de pensamento (Bollas, 1995) que possam então ser utilizadas de forma criativa e quiçá bem-humorada. Nesse sentido, bem-vindos sejam os extravios a que estamos submetidos em sala de aula. Fonte de turbulências, não há como deles escapar quando a meta é aprender em seu sentido amplo e generalizado.

\section{Aspectos da psicodinâmica grupal: a noção de grupo de suposto básico}

Segundo Outeiral (1997), a escola é também a configuração de um espaço além do espaço visível e palpável de cadeiras, classes e salas. Ela é feita de enredos montados por seus protagonistas a partir de suas histórias, seus desejos, suas veleidades, seus medos.

Na escola acontece um interjogo de forças inconscientes que se cruzam, opõem-se se opõem, se conflitam conflitam-se ou se reforçam, através de situações manifestas, claras e evidentes, ou de um sutil operar 
oculto, latente, e, nem por isso, menos operante. Cria-se uma dinâmica grupal que precisa ser compreendida. (p. 360)

Essa realidade, campo onde jogam as forças inconscientes, não pode ser objetivada, medida ou calculada. Entretanto, nem por isso essa realidade é menos real. Tão real em seus efeitos quanto os afetos das séries amor-ódio, prazer-desprazer podem ser. Dessas séries fazem parte emoções a que, quando ligadas ao pensamento, referimo-nos como sentimentos. Ligados ao pensamento, complexos e caóticos estados emocionais podem ser sentidos em suas diversas intensidades e modulações, que variam do mais cruel egoísmo ao mais generoso altruísmo.

Por um lado, a situação acadêmica exige a observância de atividades predeterminadas a serem executadas, bem como interações e sentimentos esperados por parte dos atores da situação, tais como a colaboração, a cordialidade e o respeito. No entanto, contrariando o pensamento comum, que acredita poderem ser experimentadas apenas emoções agradáveis, a psicanálise chama a atenção para as forças indesejadas das quais não se pode fugir e, por essa razão, operam fora do campo da vontade consciente. Segundo Freud (1974b) há uma característica da vida psíquica humana que as pessoas relutam em aceitar. Os homens não são criaturas gentis que desejam ser amadas e que, no máximo, querem defender-se quando atacadas. Pelo contrário, são criaturas cujos dotes instintivos comportam uma poderosa cota de agressividade que convém considerar. Por conseguinte, o próximo é não apenas um ajudante potencial, um parceiro com quem se alcançam objetivos comuns. 0 outro é também alguém a quem se faz sofrer, a quem se humilha, alguém sobre o qual se satisfaz a agressividade. A vida civilizada, por meio de seus dispositivos pedagógicos, esforça-se em estabelecer limites para as pulsões agressivas e em manter suas manifestações sob controle por formações psíquicas reativas como, por exemplo, a gentileza e a solidariedade com o próximo. Todavia, e não obstante todo o esforço de contenção, estão à espreita mundo afora provocações de diversas naturezas, prontas para despertarem moções psíquicas intensas e de origem primitiva, como o ódio, o ciúme, a inveja, a rivalidade hostil. Se não toleradas e autorizadas para então poderem, pelo pensamento, ser transmu-tadas, elas o paralisam em um nível moralizante e trivial. É justamente porque não são fáceis de ser suportadas e elaboradas pelo pensamento que as pulsões põem em risco o trabalho de aprendizagem, o qual, por sua vez, exige contenção e transformação. Criada para o trabalho, a sala de aula pode operar como um grupo de suposto básico.

A noção de "grupo de suposto básico" ou "mentalidade de suposto básico" é uma noção psicanalítica elaborada por Bion (1969), cujo escopo é dar alguma e imprescindível configuração a estados emocionais caóticos e complexos e permitir pensar fantasias e emoções segundo uma lógica afetiva. Entender a lógica emocional que regula as trocas intersubjetivas em um grupo de trabalho como a sala de aula ajuda a dar forma, voz e vez ao existente e ainda não integrado, ao pulsante e ainda sem nome.

A atividade do grupo de trabalho pode, portanto, ser tanto desviada quanto ajudada por outras atividades mentais, as de suposto básico, que têm em comum o atributo de poderosos impulsos emocionais. (p.168)

Grinberg, Sor e Bianchedi (1973) informam que os grupos funcionam muitas vezes como uma unidade, sem que os membros do grupo tenham consciência disso, a que Bion denomina de "mentalidade grupal". Vale destacar que a mentalidade grupal expressa a vontade coletiva inconsciente, unânime e anônima em momentos determinados da existência do grupo, podendo estar, entretanto, "em conflito com os desejos, opiniões ou pensamentos dos membros do grupo tomados individualmente produzindo-lhes desconforto e mal-estar" (p. 24). 
0 conflito entre, de um lado, a mentalidade grupal e, de outro, os desejos do indivíduo, é uma modalidade de conflito constitutivo das organizações grupais. Além desse, o conflito entre o desejo de saber e o desejo de não saber opera em qualquer grupo, inclusive na sala de aula. Grimberg, Sor e Bianchedi (1973) esclarecem:

Em sua participação ativa como adulto, em vários grupos, o ser humano dispõe de diferentes modos de reação. Ao reunirem-se várias pessoas para efetuar uma tarefa podem discernir-se dois tipos de tendências: uma que se dirige à realização da tarefa e outra que parece opor-se a ela. A atividade de trabalho é obstruída por uma atividade mais regressiva e primária. (p. 23)

Bion (1969) aponta para um conflito evolucionário entre o primitivo (ausência de qualquer processo de desenvolvimento) e o sofisticado (o resultante de trabalho e crescimento). Assim, é de se esperar que os estímulos para o crescimento, que despertam em maior ou menor intensidade ansiedade e medo, deparemse com reações hostis como defesa e resposta a esses mesmos estímulos, a fim de conservar a estagnação e manter o já estabelecido estabilizado, evidentemente para evitar a perturbação que qualquer mudança de estado implica.

Encontramos em Bion (apud Zimerman, 2004) uma metáfora para ilustrar ou vivificar essa modalidade paradoxal de funcionamento psíquico. Ele apresenta o seguinte trecho intitulado calma do desespero:

Uma pessoa [paciente, na situação analítica] desesperada não manifesta nenhum sentimento particularmente marcado e, algumas vezes, preferiria permanecer nesse estado, porque resulta menos perturbador do que uma possibilidade de resgate. Para dar um dramático exemplo do que quero dizer: os sobreviventes de um naufrágio estão flutuando sobre um dos restos desse naufrágio. Não estão assustados, estão desesperançosos e esfomeados. Porém, quando um barco aparece à vista, a ansiedade, o medo e o terror eclodem e a calma do desespero desaparece. Teoricamente a situação está melhor, estão a ponto de serem resgatados e salvos. Porém, em lugar de se sentirem melhor, se sentem pior. (p. 207)

Se os supostos básicos são "estados emocionais tendentes a evitar a frustração inerente ao aprendizado por experiência, aprendizado que implica esforço, dor e contato com a realidade" (Grinberg; Sor; Bianchedi, 1973, p. 28), o grupo de trabalho, em contrapartida, requer de seus membros capacidade de cooperação, o que implica tolerância à frustração e uma capacidade bem instalada de poder decepcionar-se e, em parte, conter pelo pensamento emoções muito primitivas que assolam o sujeito. A contenção significa aqui a capacidade de pensar os fluxos emocionais, senti-los e nomeá-los, em vez de agir reativamente. Ainda segundo Bion (1969):

Quanto mais o grupo se corresponde com o grupo de pressuposto básico, tanto menos uso faz de qualquer meio racional de comunicação verbal. As palavras servem de veículo para a comunicação de som. [...] Em vez de desenvolver a linguagem como um método de pensamento, o grupo usa uma linguagem existente como modo de ação. (p. 201-202)

Embora fortes laços emocionais positivos e negativos se desenvolvam espontaneamente, o grupo de suposto básico de dependência, por exemplo, estará sob o domínio de uma transferência idealizada. Isso significa que o grupo se reúne "a fim de ser sustentado por um líder, do qual depende para nutrimento material e espiritual, e para proteção" (Bion, 1969, p. 168). A idealização do líder/professor tem como contrapartida a infantilização e a submissão dos alunos, o que afeta a capacidade do grupo para pensar e para criar. Vale notar que a submissão não precisa necessariamente se apresen- 
tar ao modo da obediência passiva. Ela pode, em vez disso, aparecer na forma de queixas e ataques dirigidos ao trabalho a ser realizado ou a quem o propõe. Ela pode aparecer na forma de ataques à própria capacidade de aprender, quando o aluno se compraz lamuriento com a idéia de que nunca vai conseguir fazer o que deve ser feito. A submissão infantil pode se manifestar em modalidades diferentes da obediência servil, mas todas elas podem ser identificadas inequivocadamente a um certo negativismo perante a figura do líder/professor. A submissão tem, portanto, diversas faces. A contraposição àquilo de que se depende é uma delas. 0 negativismo, necessário para o desenvolvimento identitário da criança e do adolescente, conserva às avessas o vínculo com a autoridade da qual depende para se contrapor. Queixar-se, desobedecer, reclamar, rebelar-se, mas sempre contra as regras e os termos ditados pela autoridade, seja esta representada pela figura dos pais ou do professor'.

A figura idealizada do professor oscila entre a extrema bondade e a extrema maldade, o qual ora é visto como provedor, ora como perseguidor, mas sempre como uma figura onipotente. 0 professor é vivido como o todo-poderoso que "dá" ou "tira" a nota. 0 professor, quer queira quer não, frustra as necessidades de completa gratificação e os anseios ilimitados do grupo por amor e bondade. Por não poder tolerar a decepção decorrente da frustração, as expectativas irrealizáveis do grupo transformam-se em raiva do professor (e da instituição) e desejo de vingança. Os ataques a ele dirigidos podem assim ser interpretados como tributários da idealização gerada pelo grupo de suposto básico de dependência. Esse mecanismo é uma manifestação do infantil onipotente e mágico (mais ou menos recalcado) que coexiste com mecanismos mais realistas e amadurecidos do grupo.

Posto que a aprendizagem não é um processo espontâneo, mas fruto de trabalho e desenvolvimento, ela exige dos sujeitos alguma disposição para o enfrentamento das dificuldades inerentes ao processo. Essa disposição não impede que fantasias mágicas e onipotentes de resolução vez ou outra sejam acionadas para evitar o confronto realista com a tarefa de aprender. Como evidentemente tais fantasias não se confirmam, a experiência emocional produzida pelo vínculo do sujeito com o saber passa a ser de ódio e não de conhecimento.

Pode-se observar, com relativa frequência, que a incompreensão (esperada) de determinado conteúdo ministrado gera frustração no grupo de estudantes. Entretanto, em vez de perceber os sentimentos de raiva em si mesmos e, conseqüentemente, decepcionar-se com a auto-imagem idealizada para então poder efetivamente aprender, o grupo localiza no professor as falhas que não pode suportar em si mesmo. Ocorre que o professor pode inadvertidamente ficar aprisionado nesse jogo de projeções e identificações, sentido-se ele também frustrado por não poder corresponder ao papel de pai onipotente que o grupo o pressiona a assumir. Ao se identificar com a raiva do grupo, o professor responde sadicamente por meio de medidas disciplinares implacáveis, e assim confirma as fantasias do grupo: um professor/pai perseguidor, mau e retaliativo. Ao se queixarem de que o professor quer 'ferrar' a sala, os alunos dão expressão a essa fantasia.

\section{Aspectos da psicodinâmica grupal: a noção de identificação projetiva}

Segundo Caper (2002), essa tendência, conhecida como identificação projetiva, é automática e espontânea e não exige nenhum esforço ou pensamento consciente por parte dos participantes. Segundo Ogden (1996),

Ela representa um acontecimento psicológico interpessoal no qual o projetor, por via de uma interação interpessoal real com o recipiente da identificação projetiva, exerce pres-

1. Richard Sennett (2001), em estudo sociopolítico e psicológico sobre a autoridade, mostra como a desobediência é uma modalidade de dependência que conserva e mantém viva a autoridade. 
são sobre o outro para que se vivencie e se comporte de forma congruente com a fantasia projetiva onipotente. (p. 39)

0 que não é automático nem espontâneo e demanda trabalho interminável de elaboração psíquica é a habilidade de estabelecer uma distância suficiente das projeções a fim de reconhecê-las como tal e perceber que o estado mental que se está experimentando é efeito de um conluio: os alunos identificam o professor com o que nele projetaram e o professor se identifica com essas projeções. As projeções dos alunos, decorrentes da percepção de aspectos da personalidade do professor (em especial os inconscientes), são eficazes porque mobilizam os afetos do professor.

Sob condições favoráveis, que mereceriam ser investigadas, o professor não se identifica com aquilo que nele é projetado e não fica amarrado na trama imaginária resultante do jogo de projeções e identificações. Percebendo-se como mero suporte das idealizações e das expectativas de completude dos alunos ligadas ao pai onisciente da infância, ele sustenta sua posição na relação não idealizada com o saber. Uma relação que comporta a ignorância e a incerteza e que provoca a decepção necessária para que uma relativa autonomia (ou alguma independência) seja conquistada por seus alunos.

Fazendo eco à voz de Caper (2002), pensamos que a relação não idealizada com o conteúdo que ministramos é o que nos ajuda a sustentar nossa identidade como professor e a suportar com acolhimento as projeções de nossos alunos sem atuar responsivamente. Em condições favoráveis, somos sensiveis às necessidades emocionais dos alunos e ao mesmo tempo "irresponsivos" 2 .

Tendo em vista as vicissitudes emocionais presentes em sala de aula, não é de estranhar que um professor, que se abra para seu grupo de alunos a fim de aumentar a compreensão da relação entre ambos (o professor sempre disposto a "discutir a relação"), possa preservar e alimentar a promessa de completude e harmonia plena nas relações interpessoais. A ilusão das relações ideais entre professor e aluno gera expectativas impossíveis de serem atendidas, de modo que as frustrações e decepções se tornarão inevitáveis. Kernberg (2000), em seu estudo sobre liderança e funcionamento organizacional, chama-nos a atenção para os efeitos adversos que o excesso de abertura pode produzir. Entre eles, a ansiedade provocada por um súbito dar-se conta da impotência perante problemas que o excesso de abertura suscita e que ao grupo, de fato, não compete resolver. Existe ainda o perigo de que o professor mãezona "venha a incentivar idealizações primitivas relacionadas aos pressupostos de dependência e tais idealizações geram necessariamente decepções” (p. 75).

Quando o sujeito reconhece e admite a existência das dificuldades, ele reconhece ao mesmo tempo sua incompletude e admite seus fracassos. É de se supor que indivíduos que não toleram uma avaliação negativa, e que reagem com raiva à realidade difícil de tolerar, estão nesse momento aprisionados em fantasias de onisciência e perfeição. Êxitos e fracassos não são valores absolutos. A enorme alegria ou o desespero com que são experimentados estão relacionados a um imaginário de completude e acabamento que mantém alunos e professor narcisicamente entrelaçados. Podemos citar como exemplo o caso da aluna que, ao ouvir do professor que ele havia se equivocado na correção de uma questão, entra em um estado de enorme aflição. A aluna havia acertado a questão e ela sabia disso, mas não podia aceitar que "professores erram". Em seu imaginário, a palavra certa seria sempre a do professor, de sorte que a aluna "preferiu" recusar a percepção real de seu acerto a abdicar de seus ideais de onisciência e perfeição projetados na figura do professor/autoridade. Aceitar sua percepção implicava decepção e desilusão com a imagem que havia cultivado do professor: não foi fácil para ela aceitar que, não é porque

2. Sobre a dinâmica projetiva na clínica psicanalítica, ver Caper (2002, p. 167-187). 
sejam professores que esses seres são infalíveis, não conhecem a dúvida nem a incerteza.

Quando o professor consegue identificar alguns desses elementos projetivos, estes começam a perder sua força e sustentação. Nessa hora, é possível brincar e pensar, e se reinstala a capacidade de trabalho do grupo com a prevalência das expectativas realistas sobre a demanda de ilusões.

0 campo em que nós educadores atuamos é inevitavelmente conflitivo. Nele são mobilizados afetos muito primitivos avessos às etiquetas e às boas maneiras e que, mascarados de racionalidade, escapam ao entendimento baseado na lógica e na razão. As fantasias inconscientes, que coexistem com o pensar racional, são imunes aos juizos críticos e de realidade e, por isso, impõem-se como verdades/ crenças surdas aos argumentos racionais.

A coexistência do grupo de suposto básico e do grupo de trabalho determina um conflito permanentemente suscitado e sempre recorrente dentro do grupo. (Grinberg; Sor; Bianchedi, 1973, p. 36)

Posto que o conflito é constitutivo das relações humanas, não há alternativa senão tirar o melhor proveito daquilo que não podemos descartar. Talvez sirva de alento saber que a tensão que habita o conflito e traz o risco da desorganização é a mesma que encoraja o crescimento. Assim, operar no campo do conflito, conseqüentemente, das relações humanas, portanto, da educação, é operar em um campo de tensão carregado de riscos. Não podemos negar, entretanto, a evidência dos momentos de calmaria nas relações interpessoais. Esses são momentos bem-vindos, porque são indispensáveis para nossa economia psíquica, em que a energia é poupada (reserva psíquica) para as ações específicas. No entanto, quantos de nós também não experimentamos, vez ou outra, algum "cômodo desconforto", algum mal-estar quando essa calmaria se prolonga a tal ponto que temos a sensação de que nada se passa, de trabalho mecanizado, apatia generalizada... despersonalização.
Estamos sempre às voltas com a tensão entre, de um lado, o desejo de ordem e disciplina de nossos alunos e, de outro, o desejo de participação, interesse e atividade, ações que fazem de nosso estudante o produtor de seu conhecimento. Creio que todos nós intuímos que o pensamento criativo e produtor e não meramente reprodutor, depende em parte justamente da indisciplina, do descontrole e da desordem! Quem não se percebeu desejando de seus pupilos uma indisciplina disciplinada? Paradoxo?

\section{Uma lógica para pensar a experiência docente}

Na regência de nossas disciplinas, a experiência docente demonstra a comprovada verdade: "uma turma nunca é igual à outra". Por quê?

Quem não se sentiu frustrado ao perceber que a aula magnífica, cheia de empolgação, dada em uma turma foi pouco mais do que aborrecida, inócua até, em outra? Quem não se espantou ao se dar conta de que uma aula é "irrepetível", embora se trate ou pareça se tratar da "mesma" aula? Por que são singulares as nossas experiências com as diferentes turmas de alunos?

Pretendemos encaminhar essas questões com base nas concepções dos psicanalistas denominados intersubjetivistas. Suas idéias derivam da exploração do espaço interpessoal entre analista e paciente, em que fenômenos psíquicos são mutuamente construídos a partir da realidade psíquica singular de seus participantes. Segundo Dunn (1995):

[...] a posição intersubjetiva é de que o fenômeno mental não pode ser suficientemente compreendido se abordado como uma entidade que existe 'dentro' da mente do paciente, conceitualmente isolado da matriz social da qual emerge. (p. 201)

Em contraposição à teoria das relações de objeto desenvolvida por Melanie Klein, que aborda o espaço interpessoal como algo a ser analisa- 
do em termos intrapsíquicos, os intersubjetivistas concebem as relações subjetivas rigorosamente contextualizadas, ao modo de um jogo de mútuos endereçamentos. Eles privilegiam as relações de sujeito, cuja teoria

\section{[...] trata da interação de duas sensibilida- des humanas, que juntas criam sistemas únicos para sua coabitação [...]. A área en- tre dois sujeitos humanos no limite da dialética humana é somente um espaço em potencial. (Bollas, 1992, p. 127-128)}

A idéia a ser destacada refere-se à criação de um terceiro objeto resultante da interdependência de dois sujeitos ou subjetividades que mutuamente se constituem. Logo, a subjetividade individual não existe fora do contexto intersubjetivo. Ela produz e é produzida por esse contexto. Os fenômenos são gerados intersubjetivamente e são experimentados por seus atores de diferentes maneiras, mas reciprocamente condicionados. Algo é criado na relação professor-alunos e que chamaremos de contexto intersubjetivo, "espaço potencial", "terceiro objeto" (Ogden,1996).

Uma idéia importante destacada por Hinshelwood (2001) diz respeito ao afastamento dos intersubjetivistas da noção de unidade fechada da pessoa, característica da psicologia individual. A noção de unidade fechada da pessoa concebe as entidades professor e aluno como duas entidades distintas, autônomas e independentes que interagem. Tal noção opera segundo uma lógica identitária, que estabelece que ser é o que é; ser é ser no presente, fazendo de cada pólo da relação presença sempre idêntica a si. A lógica identitária, que pressupõe a estabilidade, a regularidade e a permanência dos entes, fixa seus próprios limites. Ela não pode aceitar e integrar a si os movimentos desestabilizantes, ignorando ou talvez até recalcando o que porventura irrompe como estranho ao universo da identidade. Essa lógica está em ação, por exemplo, em boa parte da literatura que trata do desenvolvimento inter- pessoal nas empresas. Herdeiras do ideal romântico do século XIX, as psicologias ditas humanistas, das quais essa literatura faz parte, acalentam o sonho da coincidência do sujeito consigo mesmo e da harmonia entre o indivíduo e o grupo pela via da expressão dos afetos convertidos em fetiche salvacionista ${ }^{3}$. Os percalços e as vicissitudes a que nossa vida afetiva está submetida, conforme vimos anteriormente, são suficientes para nos proteger das ilusões de redenção.

Para um pensar fecundo da experiência docente, necessitamos de uma outra lógica. Uma lógica que considere a criação de uma terceiridade no ensinar e aprender. Parafraseando Ogden, esse terceiro, sala de aula, não é redutível nem ao professor nem ao aluno. A sala de aula que se cria na tensão professor-aluno é o núcleo da experiência docente-discente. Ela permeia a dimensão cognitiva do processo ensino-aprendizagem.

Tentemos nos acercar dos movimentos que a tensão entre o par professor-aluno ou ensino-aprendizagem deflagra. Ao preparar suas aulas, o professor escolhe como abordar determinado conteúdo e fala consigo mesmo por meio da voz que criou na própria mente. Em outras palavras, ao elaborar seu plano de ensino, o professor imagina e antecipa o outro a quem será dirigida a aula. Após a aula, o professor pôde notar que:

1) A recepção do conteúdo ministrado, tão cuidadosamente preparado, não teve a repercussão desejada (pelo professor). 0 não-reconhecimento dos alunos, que permaneceram passivos, deixou-o frustrado;

2) A aula foi um sucesso. Os alunos responderam, o professor saiu da sala envaidecido e reassegurado de sua competência e de sua auto-imagem de bom professor;

3) A aula foi boa, mas (ou por isso) deixou a desejar. Ficou um mal-estar, uma certa inquietação, alguma decepção.

3. Sobre a questão dos afetos, ver o instigante tratamento a ela dado por Figueiredo (2003) no ensaio "Modernidade, trauma e dissociação: a questão do sentido hoje". 
No primeiro caso, pensamos que esse outro antecipado e imaginado não correspondeu à alteridade dos alunos. Investida narcisicamente, a alteridade do aluno é formada à imagem e semelhança do professor. Portanto, o outro (aluno) desapareceu. 0 risco de rompimento do vínculo ensino-aprendizagem é grande. É praticamente nula a sintonia docente-discente. Na melhor das hipóteses, pode vir a se instalar uma ação docente surda e por isso estereotipada.

No segundo caso, pensamos que tampouco houve aprendizagem, em que pesem as aparências. Conceitos como idealização, identificação narcisista, defesas maníacas contra a diferença traumática e traumatizante podem ser de grande valia para o desenvolvimento da segunda situação, conforme esboçamos na primeira parte deste artigo.

0 terceiro caso chama a atenção, pois parece ser justamente aquela situação que contém os ingredientes propulsores do crescimento e que está comprometida com a dialética ensino-aprendizagem. Por certo, trata-se de uma aprendizagem em que os alunos geraram uma voz a partir das palavras do professor. É a terceira voz, que não mais se reduz à voz do professor nem à escuta dos alunos. A voz gerada pelos alunos cria um outro do professor em um sentido que ultrapassa sua intencionalidade consciente. Nessa situação, professor e aluno terão criado um ao outro como sujeitos que até então não existiam (Ogden, 1996).

Explico-me. 0 professor é aquele que sabe e que tem algum controle sobre o que vai transmitir, mas, apesar disso, não pode ser apenas sujeito ao ensinar a seus alunos. Na aprendizagem, os alunos geram uma voz a partir das palavras do professor que não coincide com elas. Isso que os alunos criam é vivido pelo professor como um ensino outro, diferente do que ele intencionou ou planejou: "o aluno entendeu errado"; "não foi isso que eu falei, que eu quis dizer" são expressões e vivências muito freqüentes em nosso cotidiano docente. A menos que os alunos estejam todos delirando, e esse não parece ser o caso, podemos notar, por meio dessa experiência, como nós, professores, "somos falados" por nossos alunos, pelo outro intersubjetivo. Temos planos de ensino, intenções em sala de aula, mas não temos o controle, como gostaríamos de ter, de nossas intenções. Algo sempre escapa e permanece opaco a nossa compreensão. A inconclusividade intrínseca a nosso esforço docente refere-se, a meu ver, à criação e recriação do outro intersubjetivo, à "terceira voz", em sala de aula. A terceira voz, que não pode ser antecipada e prevista, por mais brilhantes que sejam nossos planejamentos didático-pedagógicos, desaloja-nos de nós mesmos, nos excita e nos instiga. É ela que torna possível a contínua inquietação docente e impossibilita que o esforço, algum dia, venha a cessar. A menos que...

Ocorre que essa criação do professor por seus alunos é também uma destruição da imagem que ele tem de si e do seu saber-fazer.

Indivíduos dominados pelo trauma não podem suportar a experiência de combater sua auto-identidade estática por meio do reconhecimento de uma subjetividade (eudade) que é outra para si mesmo. (Ogden, 1996, p. 2-3)

Por não poder suportar essa destruição que, em rigor, é criativa e propícia ao crescimento, o professor sente a voz outra como uma ferida narcisista em sua capacidade de ensinar e defende-se desqualificando seus alunos.

Segundo Ogden (1996):

0 confronto com a alteridade não nos dará descanso; essa percepção da outra eu-dade, uma vez registrada, não nos permitirá permanecer quem éramos e não poderemos descansar até termos de alguma forma aceitado seu ataque ao que fôramos antes de sermos interrompidos por ela. (p. 03)

Quem duvida de que uma sala de aula possa ser uma perturbação para nossa percepção e para a imagem de bom professor, claro e didático, que cultivamos de nós mesmos? Quem não precisou passar por alguma experiência 
geradora de turbulência emocional para poder genuinamente crescer como professor? Uma sala de aula pode ser dilacerante, disruptiva. Ou não. Nesse caso, o preço a pagar é a apatia e o sentimento de despersonalização.

Vemos, portanto, que uma sala de aula verdadeiramente implicada no processo ensinoaprendizagem permite, embora não os deseje, acontecimentos que escapam à vontade e ao controle de seus protagonistas. Aqui, bem como alhures, é "pela via dos afetos aparentados à surpresa, ao espanto, à frustração e à decepção" e que "abalam a segurança narcisista e impõem momentos dolorosos e desestruturantes", que se garantem momentos verdadeiramente mutativos que ensejam a aprendizagem, no nosso caso, do professor e de seus alunos. Trata-se de perdas de si e do controle dos alunos. "Quem não está psiquicamente apto a experimentar e a suportar a perda e a frustração" não pode ser um bom educador, embora "possa ser um fiel e meticuloso funcionário burocrático" do ensino (Figueiredo, 2000).

Penso que a dificuldade de suportar a angústia disparada pela perda do controle é a mesma que lança o professor na rigidez estereotipada do funcionário burocrático, que tem prontas as respostas de natureza claramente defensiva, as quais, em contrapartida, o impedem de problematizar e investigar sua prática de maneira genuína e ancorada em sua vivência dolorosamente refletida.

A vivência dolorosamente refletida pressupõe, entretanto, alguma disposição do sujeito para aceitar e sustentar a dúvida e a irresolução a que estamos de fato submetidos, mas que, conforme pontua Zygmunt Bauman (1999), constitui o "horror" do projeto de existência moderno. As "ambições planificadoras, ordenadoras e ajardinantes da modernidade" (p. 201), na feliz expressão deste, são as manifestações e a face visivel das defesas contra aqueles elementos que engendram a incerteza e a incapacidade de responder adequadamente à situação: os acasos, as contingências, os eventos fortuitos.

0 equilíbrio, a ordem e a harmonia almejados em sala de aula podem assim produzir inadvertidamente efeitos perversos. Sustentando-se na imagem daquele que sabe, que tem o controle, que domina a matéria, o professor mantém o equilíbrio hierarquizado, o qual evita a diferença, o conflito e a tensão, à custa da dissociação ou do recalcamento da voz destoante e dissonante. A estabilidade e o equilíbrio em sala de aula se convertem em ações docente e discente estereotipadas. Essa é a fonte do profundo mal-estar revelado em nossa genuína ojeriza ao que emana da posição de autoridade - o autoritarismo, caldo de cultura do grupo de suposto básico constitutivo de nosso ser-professor. 


\section{Referências bibliográficas}

BAUMAN, Z. Modernidade e ambivalência. Rio de Janeiro: Jorge Zahar, 1999.

BION, W. R. Dinâmica de grupo: uma revisão. In: KLEIN, M.; HEIMANN, P.; MONEY-KIRLE, R. E. (Orgs.). Temas de psicanálise aplicada. Rio de Janeiro: Zahar, 1969.

BOLLAS, C. Forças do destino: psicanálise e idioma humano. Rio de Janeiro: Imago, 1992.

Cracking up: the work of unconscious experience. New York: Hill and Wang, 1995.

CAPER, R. Tendo mente própria: uma visão kleiniana do self e do objeto. Rio de Janeiro: Imago, 2002.

DUNN, J. Intersubjetividade em psicanálise: uma revisão crítica. Livro Anual de Psicanálise XI, p. 201-216. São Paulo: Escuta, 1995.

FIGUEIRED0, L. C. A ética da pesquisa acadêmica e a ética da clínica em psicanálise: 0 encontro possível na pesquisa psicanalítica. 2000. Mimeo.

Psicanálise: elementos para a clínica contemporânea. São Paulo: Escuta, 2003.

FREUD, S. Algumas reflexões sobre a psicologia do escolar. In: Edição Standard Brasileira (Obras Completas de Sigmund Freud), v. XIII. Rio de Janeiro: Imago, 1974a.

. 0 mal-estar na civilização. In: Edição Standard Brasileira (Obras Completas de Sigmund Freud), v. XXI. Rio de Janeiro: Imago, 1974b.

GRINBERG, L.; SOR, D.; BIANCHEDI, E. Introdução às idéias de Bion. Rio de Janeiro: Imago, 1973.

HINSHELWOOD, R. D. Contratransferência. Livro Anual de Psicanálise, XV. São Paulo: Escuta, 2001. p. 161-182.

KERNBERG, O. F. Ideologia, conflito e liderança em grupos e organizações. Porto Alegre: Artmed, 2000.

NOSEK, L. Destruição da cultura, destruição de significados e representações. Ciência e Cultura, São Paulo, v. 56, n. 4, p. 3639, out./dez. 2004.

OGDEN, T. Os sujeitos da psicanálise. São Paulo: Casa do Psicólogo, 1996.

OUTEIRAL, J. 0. 0 trabalho com grupos na escola. Em: ZIMERMAN, D. E. et al. Como trabalhamos com grupos. Porto Alegre: Artmed, 1997.

SENNETT, R. Autoridade. Rio de Janeiro: Record, 2001.

ZIMERMAN, D. E. Bion: da teoria à prática - uma leitura didática. Porto Alegre: Artmed, 2004.

Recebido em 20.04.08

Aprovado em 11.08 .08

Vera Lúcia Blum, psicóloga, mestre em Lógica e Filosofia da Ciência pela UNICAMP e doutora em Psicologia Clínica pela PUCSP, é professora adjunta do Departamento de Psicologia do Instituto de Educação da UFMT. 